\title{
Role of PPAR $\alpha$ in the attenuation of bile acid-induced apoptosis by omega-3 long-chain polyunsaturated fatty acids in cultured hepatocytes
}

\author{
Emma M. Tillman ${ }^{1-4}$, Peihong Guan ${ }^{1,4}$, Timothy J. Howze' ${ }^{1}$ Richard A. Helms ${ }^{1,2}$ and Dennis D. Black ${ }^{2-4}$
}

\begin{abstract}
BACKGROUND: Omega-3 long-chain polyunsaturated fatty acids ( $\omega 3$ PUFA) have been shown to be antiinflammatory in the attenuation of hepatocellular injury. Peroxisome proliferator-activated receptor alpha (PPAR $\alpha$ ) is a nuclear receptor transcription factor that inhibits the activation of nuclear factor $\kappa B$, thereby repressing inflammation, and WPUFA are PPAR $\alpha$ ligands. The purpose of this study was to determine if $\omega 3$ PUFA attenuate bile acid-induced apoptosis via PPAR $\alpha$.

METHODS: Human hepatocellular carcinoma (HepG2) cells were treated with chenodeoxycholic acid (CDCA) \pm (3) PUFA. Activation of PPAR $\alpha$ was evaluated, and expression of PPAR $\alpha$, farnesoid $X$ receptor, liver $X$ receptor alpha ( $L X R \alpha)$, and retinoid $X$ receptor $m R N A$ was evaluated by reverse-transcriptase $P C R$.

RESULTS: PPAR $\alpha$ activation was increased in HepG2 cells treated with $\omega 3$ PUFA, and decreased in the presence of CDCA when compared with untreated cells. PPAR $\alpha$ mRNA was reduced by $67 \%$ with CDCA and restored to the level of control with $\omega 3$ PUFA. LXR $\alpha$ mRNA increased twofold with CDCA treatment and was significantly reduced by $\omega 3$ PUFA.

CONCLUSION: Expression of PPARa, as well as LXRa mRNA levels, was reduced with CDCA treatment and restored with the addition of W3PUFA. These results suggest that PPARa and LXRa may be mediators by which w3PUFA attenuate bile acid-induced hepatocellular injury.
\end{abstract}

$\mathbf{P}$ eroxisome proliferator-activated receptor alpha (PPARa) is a nuclear receptor transcription factor that regulates lipid metabolism. When bound to a ligand, PPARa forms a heterodimer with retinoid $\mathrm{X}$ receptor (RXR) that binds to the peroxisome proliferator response element in the promoter region of target genes and modulates transcription as depicted in Figure 1. Activation of PPARa inhibits nuclear factor $\kappa B$ $(\mathrm{NF} \kappa \mathrm{B})$ activation, and consequently repressing inflammation $(1,2)$. Hepatic nuclear receptor RXR has also been shown to be important in hepatic responses to inflammation (3). Alternatively, NFKB activation increases expression of antiapoptotic genes, such as the caspase- 8 inhibitor c-FLIP, which could lead to resistance to Fas ligand and/or tumor necrosis factor-dependent apoptosis (4). Previous studies have shown omega-3 long-chain polyunsaturated fatty acids ( $\omega 3$ PUFA) to be a PPARa ligand, thereby inhibiting NFkB activation (2). In studies where PPAR $a$ null mouse hepatocytes treated with nafenopin (a peroxisome proliferator), apoptosis was not suppressed, although treatment with tumor necrosis factor- $\alpha$ was able to suppress apoptosis in PPAR $\alpha$ null hepatocytes (5). These studies demonstrated that PPAR $\alpha$ mediates hepatocyte apoptosis, yet high concentrations of tumor necrosis factor- $\alpha$ can modulate and/or negate this response (5). These results suggest that PPAR $\alpha$ inhibition of NFKB may play an important role in the overall cellular innate immune response and cell survival. The pathways affected by PPAR $\alpha$ and NFkB are complex and in some cases, seemingly contradictory. These contradictory effects of $\mathrm{NFKB}$ on apoptosis have perplexed investigators studying interferon-mediated activation of $\mathrm{NF \kappa B}$, where this results in antiviral and proapoptotic activity. There is also evidence that micro-RNAs may have an important role in this complex signaling pathway (6). Finally, PPARa is known to inhibit apoptosis via NFkB-independent pathways, such as upregulation of the 14-3-3 proteins (7). The suppression of proinflammatory cytokine transcription by PPAR $a$ via NFkB would support our hypothesis, but the NFkB-mediated suppression of antiapoptotic pathways would suggest that $\omega 3$ PUFA activation of PPARa could result in increased apoptosis.

Omega-3 PUFA have been shown to be antiinflammatory and immunomodulatory in the attenuation of cellular injury (8-13). Recently, there has been much interest in the use of fish oil contacting $\omega 3$ PUFA to treat parenteral nutrition-associated liver disease (PNALD) in children (14). Interestingly, w3PUFA have been shown to paradoxically inhibit apoptosis and sensitize the cells to apoptosis (15-18). It is established that the composition and levels of free fatty acids can significantly alter cell survival pathways. Free fatty acids have been shown to inhibit serum-starved apoptosis in a murine cell model via the G-coupled protein receptor, GPR120 (19). In these experiments, both saturated and unsaturated free fatty acid-enhanced

'Department of Clinical Pharmacy, The University of Tennessee Health Science Center, Memphis, Tennessee; ${ }^{2}$ Department of Pediatrics, The University of Tennessee Health Science Center, Memphis, Tennessee; ${ }^{2}$ Le Bonheur Children's Hospital, Memphis, Tennessee; ${ }^{4}$ Children's Foundation Research Institute, Memphis, Tennessee. Correspondence: Emma M. Tillman (etillman@uthsc.edu)

Received 27 June 2015; accepted 28 October 2015; advance online publication 3 February 2016. doi:10.1038/pr.2016.2 


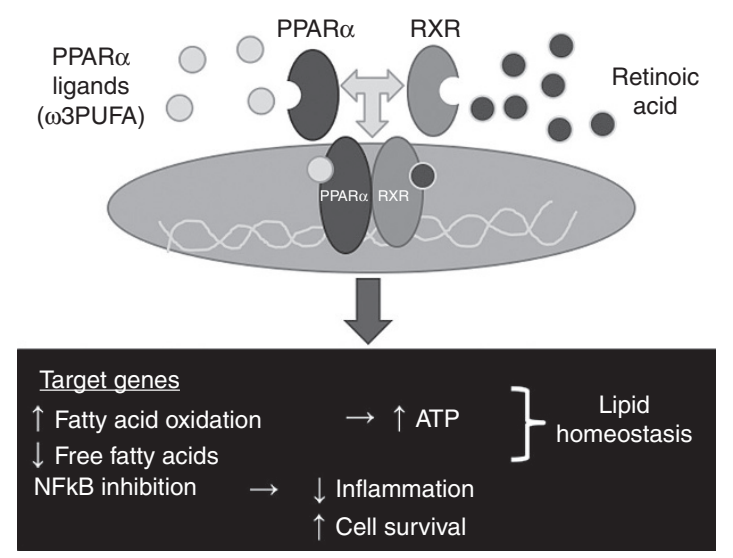

Figure 1. PPAR $\alpha$ transcriptional activity. This figure is an illustration of PPAR $\alpha$ transcription and its effects on lipid homeostasis and NFKB activation. PPAR $\alpha$, peroxisome proliferator-activated receptor alpha.

cell survival, but linolenic acid, palmitoleic acid, and docosahexaenoic acid (DHA) had the most potent effects on cell survival (20). In addition, GPR120 has recently been shown to be a receptor or sensor for 13 PUFA, mediating regulation of inflammation, and inhibiting both toll-like receptor $2 / 3 / 4$ and tumor necrosis factor- $\alpha$ cascades (21). Both NFKB and c-Jun $\mathrm{N}$-terminal kinases have been shown to play a role in the upregulation of death receptors in the presence of noxious stimuli $(22,23)$.

In the present studies, we hypothesized that $\omega 3$ PUFA would modulate PPAR $\alpha$ activaton and/or mRNA levels resulting in the attenuation of hydrophobic bile acid-induced apoptosis via PPAR $\alpha$ downstream effects. Expression of liver X receptor alpha $(\mathrm{LXR} \alpha)$ and farnesoid X receptor (FXR) was also studied, as these nuclear receptors are recognized mediators of diverse metabolic pathways in liver, including inflammation, apoptosis and fibrosis $(24,25)$.

\section{RESULTS}

\section{PPAR $\alpha$ Activity}

As shown in Figure 2, treatment of Human hepatocellular carcinoma (HepG2) cells with $\omega 3$ PUFA alone resulted in increased PPAR $\alpha$ activity compared with controls and levels were statistically equal to that observed with positive control (recombinant PPAR $\alpha$ ). Treatment with $\omega 3$ PUFA was increased $37 \%$ over untreated cells and DNA binding of PPAR $\alpha$ was decreased by $45 \%$ in the presence of chenodeoxycholic acid (CDCA) $(P<0.001)$. There was a modest, trend to restoration (only decreased by $30 \%$ as compared with $45 \%$ ) of PPAR $\alpha$ activity to untreated control levels with the addition of $\omega 3$ PUFA in the setting of CDCA treatment.

\section{PPAR $\alpha$, LXR $\alpha$, FXR, and RXR mRNA Levels}

Treatment with CDCA alone resulted in $67 \%$ reduction in PPAR $\alpha$ mRNA, as compared with cells treated with a vehicle control (Figure 3a). Treatment with CDCA alone resulted in a twofold increase in LXR $\alpha$ mRNA that was attenuated by the addition of $\omega 3$ PUFA (Figure 3b). No significant changes

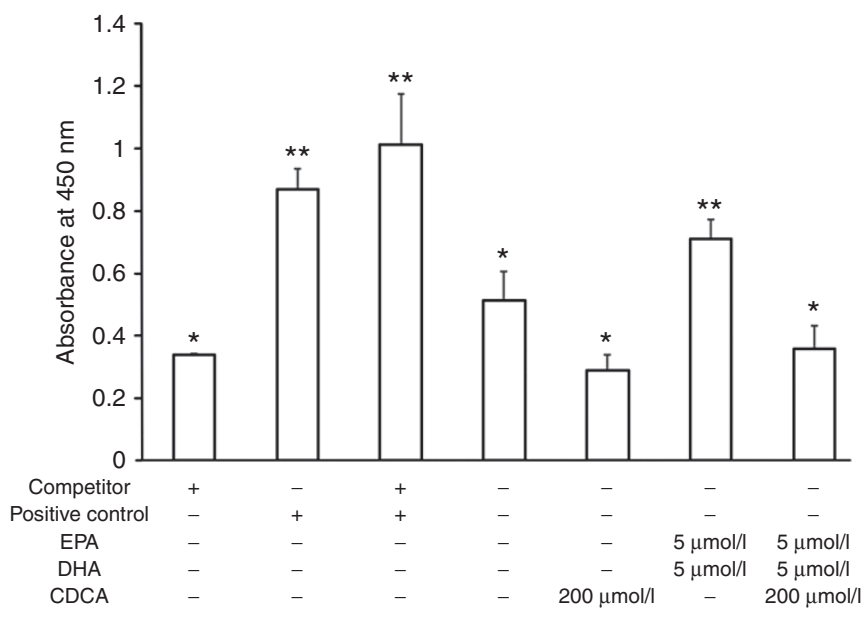

Figure 2. PPAR $\alpha$ activity. PPAR $\alpha$ activity in HepG2 cells treated with CDCA with and without 13 PUFA. Values are based on a fold change relative to the vehicle control. Statistical significance was determined using an ANOVA with Tukey's LSD. Each bar represents mean \pm SEM for data from three culture wells. Statistical significance was determined using an ANOVA with Tukey's LSD. Means of data from various treatment conditions with different letters above the bars are significantly different from each other at $P<0.05$ by ANOVA. Those bars sharing the same symbol or no symbol are not significantly different from each other. PPAR $\alpha$, peroxisome proliferatoractivated receptor alpha; CDCA, chenodeoxycholic acid; $\omega 3$ PUFA, omega-3 long-chain polyunsaturated fatty acids. LSD, least significant difference.

in RXR or FXR mRNA levels were observed with either treatment (data not shown).

Role of PPAR $\alpha$ in the Attenuation of Bile Acid-Induced Apoptosis As shown in Figure 4, HepG2 cells treated with 13 PUFA, in addition to the CDCA challenge, exhibited a $47 \%$ attenuation of apoptosis, as reflected by caspase-3/7, when compared with cells treated with CDCA alone. This $\omega 3$ PUFA protective effect was not observed with blockade of PPAR $\alpha$ with specific antibody. With antibody dose escalation, there was no significant difference in caspase-3/7 with increasing doses of antibody. These results suggest that the attenuation of apoptosis occurs via PPAR $\alpha$-dependent pathways.

\section{DISCUSSION}

The present studies support a role for PPAR $\alpha$ in protection from bile acid-induced apoptosis in hepatocytes and may, at least partially, mediate the attenuation of apoptosis by W3PUFA, which may represent one mechanism for the positive effect of $\omega 3$ PUFA treatment in PNALD. Activation and mRNA levels of PPAR $\alpha$ were reduced by treatment with the lipophilic bile acid, CDCA, at a dose associated with hepatocyte apoptosis. When hepatocytes were exposed to 13 PUFA alone, PPAR $\alpha$ activity and mRNA levels were increased. When cells were treated with CDCA with the addition of $\omega 3$ PUFA, PPAR $\alpha$ mRNA levels were similar to those of control cells, and there was a trend to restoration of PPAR $\alpha$ activation. Our findings are consistent with studies of CFTR-knockout mice and isolated macrophages from CFTR-knockout mice in which pretreatment with DHA resulted in increased PPAR $\alpha$ mRNA levels. This increase was blocked by the addition of 


\section{Articles | Tillman e tal.}

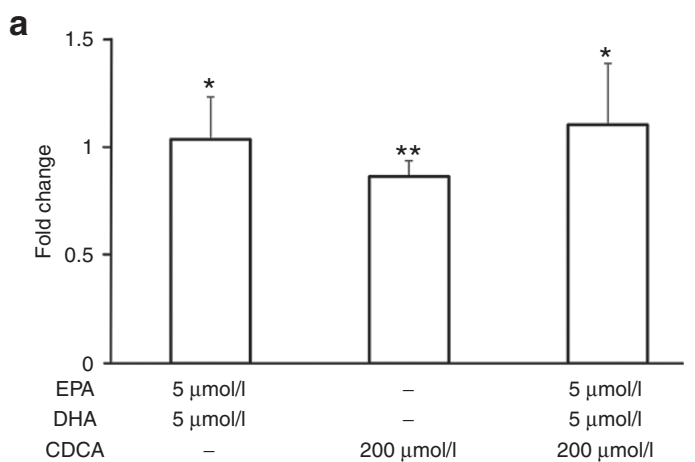

b

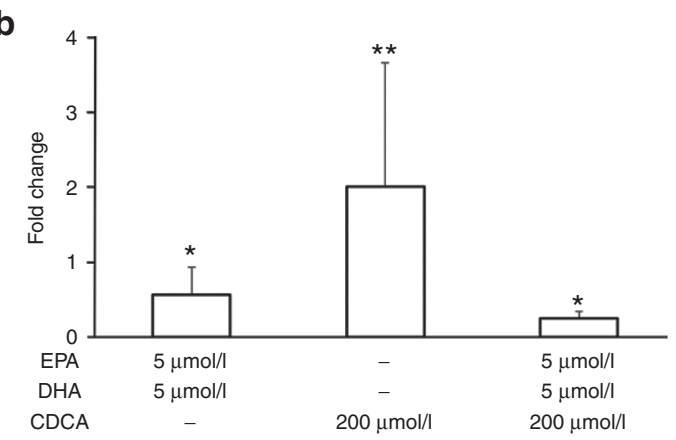

Figure 3. PPAR $\alpha$ and LXR $\alpha$ mRNA levels. (a) PPAR $\alpha$, (b) LXR $\alpha$ mRNA levels were measured by quantitative RT-PCR. Values are based on a fold change relative to the vehicle control. Statistical significance was determined using an ANOVA with Tukey's LSD. Each bar represents mean \pm SEM for data from three culture wells. Statistical significance was determined using an ANOVA with Tukey's LSD. Means of data from various treatment conditions with different letters above the bars are significantly different from each other at $P<0.05$ by ANOVA. Those bars sharing the same symbol or no symbol are not significantly different from each other. PPAR $\alpha$, peroxisome proliferator-activated receptor alpha; $L X R \alpha$, liver $X$ receptor alpha; RT-PCR, reverse-transcriptase PCR. LSD, least significant difference.

a PPAR $\alpha$ antagonist $(26,27)$. In contrast, studies in a mouse model of PNALD using PPAR $\alpha$-knockout and wild-type mice resulted in increased hepatic triglyceride concentrations in both WT and KO mice treated with PN with the addition of $\omega 3$ PUFA and $\omega 6$ PUFA as compared with chow fed mice (28). However, animals receiving $\omega 3$ PUFA had lower hepatic triglyceride content compared with animals fed $\omega 6$ PUFA in both WT and KO mice. Therefore, the investigators concluded that 13 PUFA attenuation of hepatic triglyceride accumulation in this model of PNALD is not via PPAR $\alpha$-dependent pathways (28). While the effects of 13 PUFA on hepatic triglyceride accumulation may not be PPAR $\alpha$ dependent in this in vivo model of PNALD, we have shown in the present studies in an in vitro model that bile acid-induced apoptosis often associated with PNALD is attenuated by 13 PUFA via PPAR $\alpha$-dependent pathways. This is not surprising in light of the complex and multifactorial nature of PNALD pathogenesis, which involves hepatocellular injury, inflammation, and apoptosis in addition to steatosis. Our data support the hypothesis that $\omega 3$ PUFA are functioning, at least partially, via PPAR $\alpha$-dependent mechanisms to attenuate direct bile acid-induced apoptosis. The mechanisms by which $\omega 3$ PUFA

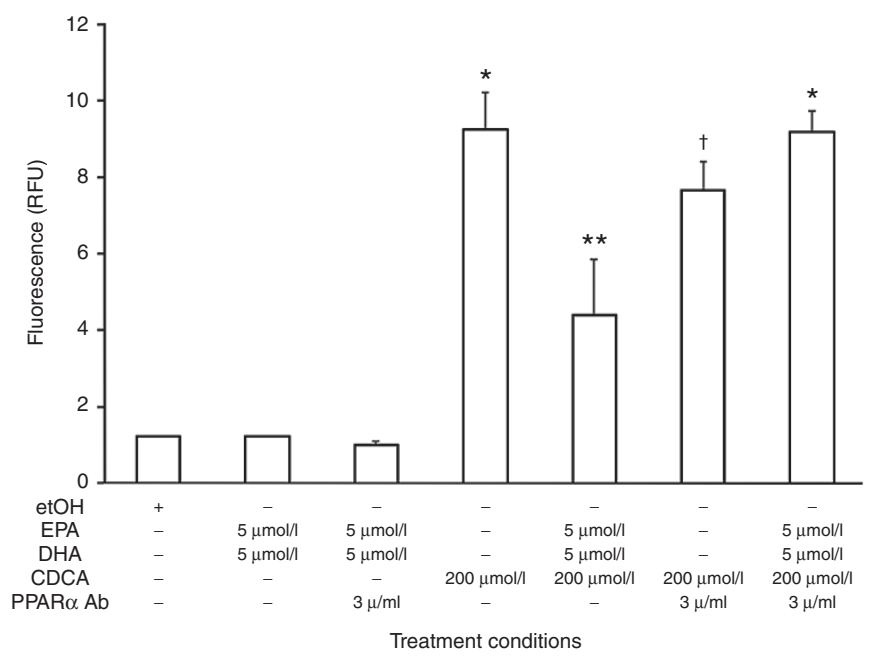

Figure 4. Caspase-3/7 activity. Bile acid-induced apoptosis evaluated by caspase-3/7 with and without the addition of an antibody specific to PPAR $\alpha$ with $\omega 3$ PUFA treatment. Data are represented based on relative fluorescence units above control. Each bar represents mean \pm SEM for data from three independent experiments. Statistical significance was determined using an ANOVA with Tukey's LSD. Means of data from various treatment conditions with different letters above the bars are significantly different from each other at $P<0.05$ by ANOVA. Those bars sharing the same symbol or no symbol are not significantly different from each other. PPAR $\alpha$, peroxisome proliferator-activated receptor alpha; $\omega 3$ PUFA, omega-3 long-chain polyunsaturated fatty acids. LSD, least significant difference.

reduce hepatic steatosis may indeed occur independently of PPAR $\alpha$.

For these experiments, we chose to use an equal molar ratio of eicosapentaenoic acid to DHA, because our group has previously shown eicosapentaenoic acid and DHA to be synergistic in the attenuation of bile acid induce apoptosis (29). We observed a 67\% reduction in PPAR $\alpha$ mRNA levels when cells were treated with CDCA as compared with cells treated with a vehicle control. The addition of $\omega 3$ PUFA resulted in restoration to the level of control cells. We did not observe a significant difference in RXR mRNA levels, which was not unexpected, since abundance of RXR and its ligand, cis retinoic acid, typically precludes it from becoming rate limiting in its role as a heterodimer partner with transcription factors.

Treatment with CDCA alone resulted in a twofold increase in LXR $\alpha$ mRNA levels that was attenuated by the addition of (3) PUFA. It is noteworthy that LXR $\alpha$ has been shown to have specific roles in regulating the innate immune response (30). Also, studies in LXR $\alpha$ null macrophages have shown that LXR $\alpha$ has an important role in both innate and adaptive immunity, specifically in apoptosis (31). Cancer cells of diverse origin may be programmed to enter apoptosis by LXR $\alpha$ activation (32).Therefore, it is possible that LXR $\alpha$ may be an important mediator of CDCA-induced apoptosis, and its suppression by W3PUFA may represent an additional pathway for the beneficial effect of $\omega 3$ PUFA on apoptosis. Interestingly, FXR mRNA abundance was not affected by CDCA or $\omega 3$ PUFA treatment.

In summary, these studies suggest roles for PPAR $\alpha$, as well as LXR $\alpha$, in the regulation of bile acid-induced apoptosis in hepatocytes and its suppression by 63 PUFA. It is possible that 
PPAR $\alpha$ activation and LXR $\alpha$ suppression may be promising mechanisms by which $\omega 3$ PUFA attenuate the bile acid-induced hepatocellular injury that occurs in cholestatic liver disease, such as that seen in PNALD. However, these conclusions must be tempered by several caveats. First, these studies were performed in a cell culture system using hepatoma-derived hepatocytes. Second, we explored but one mechanism of cell injury, bile acid toxicity, and its induction of apoptosis, whereas multiple pathogenic mechanisms are operative in clinical PNALD. Finally, more work will be required to further define additional potential pathways involved in these observed $\omega 3$ PUFA effects and to translate these findings to useful therapy for PNALD in human infants.

\section{METHODS \\ Cell Culture}

Because this was an in vitro study and did not involve the use of human subjects or animals, the University of Tennessee Health Science Center did not require approval by the Institutional Review Board. Cell culture experiments were performed using HepG2 cells obtained from the American Type Culture Collection (Rockville, MD). Cell culture experiments used standard medium, incubation conditions, and passages according to the supplier's instructions. HepG2 cells were treated with CDCA $(200 \mu \mathrm{mol} / \mathrm{l})$ (Sigma-Aldrich, St. Louis, MO) with and without the addition of $\omega 3$ PUFA $(5 \mu \mathrm{mol} / \mathrm{l}$ eicosapentaenoic acid combined with $5 \mu \mathrm{mol} / \mathrm{l} \mathrm{DHA}$ ) (Sigma-Aldrich). Concentrations of CDCA and 13 PUFA for these experiments were based on our previously published work (29).

\section{PPAR $\alpha$ Activation}

Activation of PPAR $\alpha$ was evaluated by isolation of nuclear protein after 4 -h treatment and measured by assessing transcription factor activity in a nonradioactive, sensitive ELISA method for detecting PPAR $\alpha$ DNA binding activity in nuclear extracts (PPAR $\alpha$ Transcription Factor Assay Kit, Cayman Chemical, Ann Arbor, MI). This kit contained a positive control of clarified cell lysate and a competitor of double-strand DNA.

\section{PPAR $\alpha$ mRNA Analysis}

HepG 2 cells were treated with $200 \mu \mathrm{mol} / \mathrm{l}$ CDCA $\pm \omega 3$ PUFA for $0.5 \mathrm{~h}$, and PPAR $\alpha, \mathrm{LXR} \alpha, \mathrm{FXR}$, and RXR mRNA levels were evaluated by reverse-transcriptase PCR using an ABI 7500 Sequence Detector and SYBR Green PCR Master Mix according to the manufacturer's instructions. Levels of mRNA were normalized to $18 \mathrm{~s}$ ribosomal RNA quantified simultaneously in a multiplex reverse-transcriptase PCR reaction. Specific primers were designed for the genes of interest (PPAR $\alpha, F X R, L X R \alpha$, and RXR). See Table 1 for primer sequences. All samples were analyzed in triplicates.

Table 1. Reverse-transcriptase PCR (RT-PCR) primer sequences

\begin{tabular}{|c|c|}
\hline Primer & Sequence \\
\hline \multirow[t]{2}{*}{$18 \mathrm{~s}$} & F: 5'-CTCAACACGGGAAACCTCAC-3' \\
\hline & R: 5'-TTATCGGAATTAACCAGACAAATCG-3' \\
\hline \multirow[t]{2}{*}{ PPAR $\alpha$} & F: 5'-GTAGAATCTGCGGGGACAAG-3' \\
\hline & R: 5'-TGTGACATCCCGACAGAAAG-3' \\
\hline \multirow[t]{2}{*}{ FXR } & F: 5'-CTACCAGGATTTCAGACTTTGGAC-3' \\
\hline & R: $5^{\prime}$-GAACATAGCTTCAACCGCAGAC-3' \\
\hline \multirow[t]{2}{*}{$\operatorname{LXR} \alpha$} & F: 5'-CCGCTCGAGATGTCCTTGTGGCTGG-3' \\
\hline & R: 5'-CGCTCTAGATCATTCGTGCACATCC-3' \\
\hline \multirow[t]{2}{*}{$\mathrm{RXR}$} & F: 5'-AAGGACCGGAACGAGAATGA-3' \\
\hline & R: 5'-ATCCTCTCCACCGGCATGT-3' \\
\hline
\end{tabular}

\section{Caspase 3/7 Activity}

In order to determine if the attenuation of bile acid-induced apoptosis by $\omega 3$ PUFA occurs via PPAR $\alpha$-dependent pathways, HepG2 cells were treated with a PPAR $\alpha$ polyclonal antibody (PPAR $\alpha$ H-98: sc-9000) purchased from Santa Cruz Biotechnology (Dallas, TX), and apoptosis was evaluated using caspase-3/7. Cultured HepG2 cells were treated with $\omega 3$ PUFA (eicosapentaenoic acid $5 \mu \mathrm{mol} / \mathrm{l}+\mathrm{DHA} 5$ $\mu \mathrm{mol} / \mathrm{l}$ ) alone; $200 \mu \mathrm{mol} / \mathrm{l} \mathrm{CDCA}$ alone; and then with the combinations $\omega 3$ PUFA, and varying concentrations of PPAR $\alpha$ antibody (3-10 $\mu \mathrm{g} / \mathrm{ml}$ ). Apoptosis was evaluated using the Apo-ONE Homogeneous Caspase-3/7 Assay purchased from Promega Corporation (Madison, WI) and performed according to the manufacturer's instructions. HepG2 cells were treated for $12 \mathrm{~h}$ followed by the addition of caspase-3/7 reagent and incubation for $4 \mathrm{~h}$ in the dark on a rocking shaker at low speed. Results were read at fluorescein $485 / 535 \mathrm{~nm}$ with a Victor 2, Perkin-Elmer Wallace 1420 multilabel counter (Shelton, CT) as previously described (29).

\section{Statistical Analysis}

All data represent at least three separate and independent experiments. Data are depicted as mean \pm SEM. A one-way ANOVA was used to compare differences between groups and a post-hoc Tukey's HSD (honestly significant difference) test was used to correct for multiple comparisons. A two-tailed $P$ value of 0.05 was used to reject the null hypothesis.

\section{STATEMENT OF FINANCIAL SUPPORT}

This research was supported by a Le Bonheur Children's Hospital Junior Faculty Grant, Memphis, TN.

Disclosure: The authors of this manuscript do not hold any financial ties to products in the study or potential/perceived conflicts of interest; there are no disclosures.

\section{REFERENCES}

1. Bishop-Bailey D. Peroxisome proliferator-activated receptors in the cardiovascular system. Br J Pharmacol 2000;129:823-34.

2. Mishra A, Chaudhary A, Sethi S. Oxidized omega-3 fatty acids inhibit NF-kappaB activation via a PPARalpha-dependent pathway. Arterioscler Thromb Vasc Biol 2004;24:1621-7.

3. Kosters A, White DD, Sun H, Thevananther S, Karpen SJ. Redundant roles for cJun-N-terminal kinase 1 and 2 in interleukin-1beta-mediated reduction and modification of murine hepatic nuclear retinoid $\mathrm{X}$ receptor alpha. J Hepatol 2009;51:898-908.

4. Micheau O, Lens S, Gaide O, Alevizopoulos K, Tschopp J. NF-kappaB signals induce the expression of c-FLIP. Mol Cell Biol 2001;21:5299-305.

5. Hasmall SC, James NH, Macdonald N, Gonzalez FJ, Peters JM, Roberts RA. Suppression of mouse hepatocyte apoptosis by peroxisome proliferators: role of PPARalpha and TNFalpha. Mutat Res 2000;448:193-200.

6. Yang CH, Yue J, Fan M, Pfeffer LM. IFN induces miR-21 through a signal transducer and activator of transcription 3-dependent pathway as a suppressive negative feedback on IFN-induced apoptosis. Cancer Res 2010;70:8108-16.

7. Wu KK. Peroxisome proliferator-activated receptors protect against apoptosis via 14-3-3. PPAR Res 2010;2010:417646.

8. Alwayn IP, Gura K, Nosé V, et al. Omega-3 fatty acid supplementation prevents hepatic steatosis in a murine model of nonalcoholic fatty liver disease. Pediatr Res 2005;57:445-52.

9. De Vizia B, Raia V, Spano C, Pavlidis C, Coruzzo A, Alessio M. Effect of an 8-month treatment with omega-3 fatty acids (eicosapentaenoic and docosahexaenoic) in patients with cystic fibrosis. JPEN J Parenter Enteral Nutr 2003;27:52-7.

10. Adkins Y, Kelley DS. Mechanisms underlying the cardioprotective effects of omega-3 polyunsaturated fatty acids. J Nutr Biochem 2010;21:781-92.

11. Schmöcker C, Weylandt KH, Kahlke L, et al. Omega-3 fatty acids alleviate chemically induced acute hepatitis by suppression of cytokines. Hepatology 2007;45:864-9.

12. Takatsuka H, Takemoto $\mathrm{Y}$, Iwata N, et al. Oral eicosapentaenoic acid for complications of bone marrow transplantation. Bone Marrow Transplant 2001;28:769-74. 


\section{Articles | Tillman e tal.}

13. Singer P, Shapiro H, Theilla M, Anbar R, Singer J, Cohen J. Anti-inflammatory properties of omega-3 fatty acids in critical illness: novel mechanisms and an integrative perspective. Intensive Care Med 2008;34:1580-92.

14. Tillman EM. Review and clinical update on parenteral nutrition-associated liver disease. Nutr Clin Pract 2013;28:30-9.

15. Park KS, Lim JW, Kim H. Inhibitory mechanism of omega-3 fatty acids in pancreatic inflammation and apoptosis. Ann N Y Acad Sci 2009;1171: 421-7.

16. Malhi H, Barreyro FJ, Isomoto H, Bronk SF, Gores GJ. Free fatty acids sensitise hepatocytes to TRAIL mediated cytotoxicity. Gut 2007;56:1124-31.

17. Pusl T, Wild N, Vennegeerts T, et al. Free fatty acids sensitize hepatocytes to bile acid-induced apoptosis. Biochem Biophys Res Commun 2008;371:441-5.

18. Shimojo N, Jesmin S, Zaedi S, et al. Changes in important apoptosisrelated molecules in the endothelin-1-induced hypertrophied cardiomyocytes: effect of the pretreatment with eicosapentaenoic acid. Exp Biol Med (Maywood) 2006;231:932-6.

19. Katsuma S, Hatae N, Yano T, et al. Free fatty acids inhibit serum deprivation-induced apoptosis through GPR120 in a murine enteroendocrine cell line STC-1. J Biol Chem 2005;280:19507-15.

20. Hirasawa A, Hara T, Katsuma S, Adachi T, Tsujimoto G. Free fatty acid receptors and drug discovery. Biol Pharm Bull 2008;31:1847-51.

21. Oh DY, Talukdar S, Bae EJ, et al. GPR120 is an omega-3 fatty acid receptor mediating potent anti-inflammatory and insulin-sensitizing effects. Cell 2010;142:687-98.

22. Mendoza FJ, Ishdorj G, Hu X, Gibson SB. Death receptor-4 (DR4) expression is regulated by transcription factor NF-kappaB in response to etoposide treatment. Apoptosis 2008;13:756-70.
23. Higuchi H, Gores GJ. Bile acid regulation of hepatic physiology: IV. Bile acids and death receptors. Am J Physiol Gastrointest Liver Physiol 2003;284:G734-8.

24. Ali AH, Carey EJ, Lindor KD. Recent advances in the development of farnesoid X receptor agonists. Ann Transl Med 2015;3:5.

25. Chen WD, Wang YD, Meng Z, Zhang L, Huang W. Nuclear bile acid receptor FXR in the hepatic regeneration. Biochim Biophys Acta 2011;1812: 888-92.

26. Andersson C, Zaman MM, Jones AB, Freedman SD. Alterations in immune response and PPAR/LXR regulation in cystic fibrosis macrophages. J Cyst Fibros 2008;7:68-78.

27. Ollero M, Junaidi O, Zaman MM, et al. Decreased expression of peroxisome proliferator activated receptor gamma in cftr-/- mice. J Cell Physiol 2004;200:235-44.

28. Prince E, Lazare FB, Treem WR, et al. $\Omega-3$ fatty acids prevent hepatic steatosis, independent of PPAR- $\alpha$ activity, in a murine model of parenteral nutrition-associated liver disease. JPEN J Parenter Enteral Nutr 2014;38:608-16.

29. Tillman EM, Helms RA, Black DD. Eicosapentaenoic acid and docosahexaenoic acid synergistically attenuate bile acid-induced hepatocellular apoptosis. JPEN J Parenter Enteral Nutr 2012;36:36-42.

30. Im SS, Osborne TF. Liver $\mathrm{x}$ receptors in atherosclerosis and inflammation. Circ Res 2011;108:996-1001.

31. A-Gonzalez N, Bensinger SJ, Hong C, et al. Apoptotic cells promote their own clearance and immune tolerance through activation of the nuclear receptor LXR. Immunity 2009;31:245-58.

32. Mehrotra A, Kaul D, Joshi K. LXR- $\alpha$ selectively reprogrammes cancer cells to enter into apoptosis. Mol Cell Biochem 2011;349:41-55. 